\title{
Mucocele of the appendix: Incidental finding of a rare occurrence
}

\author{
Ashish Bahadur Malla, MS; Rakesh Kumar Sah, MS, MCh \\ Department of General Surgery, Digestive Diseases and Laparoscopic Surgery, Grande International Hospital, \\ Kathmandu, Nepal
}

\section{Corresponding author}

Ashish B Malla, MS

email: ashirc88@gmail.com

Received 13 Dec 2018

Accepted 21 Dec 2018

\begin{abstract}
Mucocele of the appendix is a rare disease. Clinically, appendeceal mucocele (AM) is an incidental finding or it may mimic appendicitis. In AM, distension of the appendix is caused by mucus, the source of which can be benign or malignant. For the benign disease, appendectomy alone is sufficient but for malignant conditions adjunct treatments are needed. Proper pre-operative evaluation is imperative to distinguish between benign and malignant causes in order to guide the management and reduce complications. For the definitive diagnosis, histology and immunohistochemistry are required. We report an incidental finding of an appendeceal mucocele in a kidney donor during pre-transplant evaluation.
\end{abstract}

\section{Introduction}

Mucocele of the appendix is dilatation of appendix due to obstructive pathology caused by intra luminal mucoid material accumulation ${ }^{1,2}$. Clinically, appendeceal mucocele (AM) is an incidental finding or it may mimic acute appendicitis (AA). Preoperative investigations help distinguish between $A A$ and $A M$ to decide the best surgical approach to prevent peritoneal spillage regardless of the etiology.

We report an incidental finding of an $A M$ in a 55-year-old prospective kidney donor during her pre-transplant evaluation.

\section{Case report}

A 55-year-old female presented in surgical outpatient clinic. Patient was a would-be kidney donor to her daughter. Clinical examination during preoperative evaluation suggested a right iliac fossa mass. There was no significant past history relating to the mass. Rest of the systemic examinations were unremarkable. Provisional diagnosis of renal cyst or caecal tumor was made. Abdominal ultrasonography revealed an avascular tubular structure with calcified and echogenic debris and the tip abutting the lower pole of right kidney $(9.4 \times 4 \times 3.5 \mathrm{~cm})$. Her biochemical investigations including CEA and CA19-9 were normal. Contrast enhanced CT (Fig. 1) was suggestive of AM.

On laparoscopic evaluation, a mass was seen originating from the appendix lateral to the caecum which was excised. The histopathological examination showed retention cyst of the appendix which was negative for malignancy ${ }^{2,3}$. She had an uneventful recovery.

\section{Discussion}

Appendectomy is one of the most commonly performed gastrointestinal surgeries worldwide. $A M$ is a relatively uncommon disease and may present as an incidental finding or is discovered on pathological examination ${ }^{4}$. The incidence of AM is $0.2 \%$ to $0.4 \%$ in the entire appendectomy specimen $^{3}$. It is of benign or malignant type which is differentiated histologically, $y^{3,5}$.

Rokitansky was the first to describe mucocele of appendix in $1942^{6}$. AM is described as appendix distended by mucus, due to any 


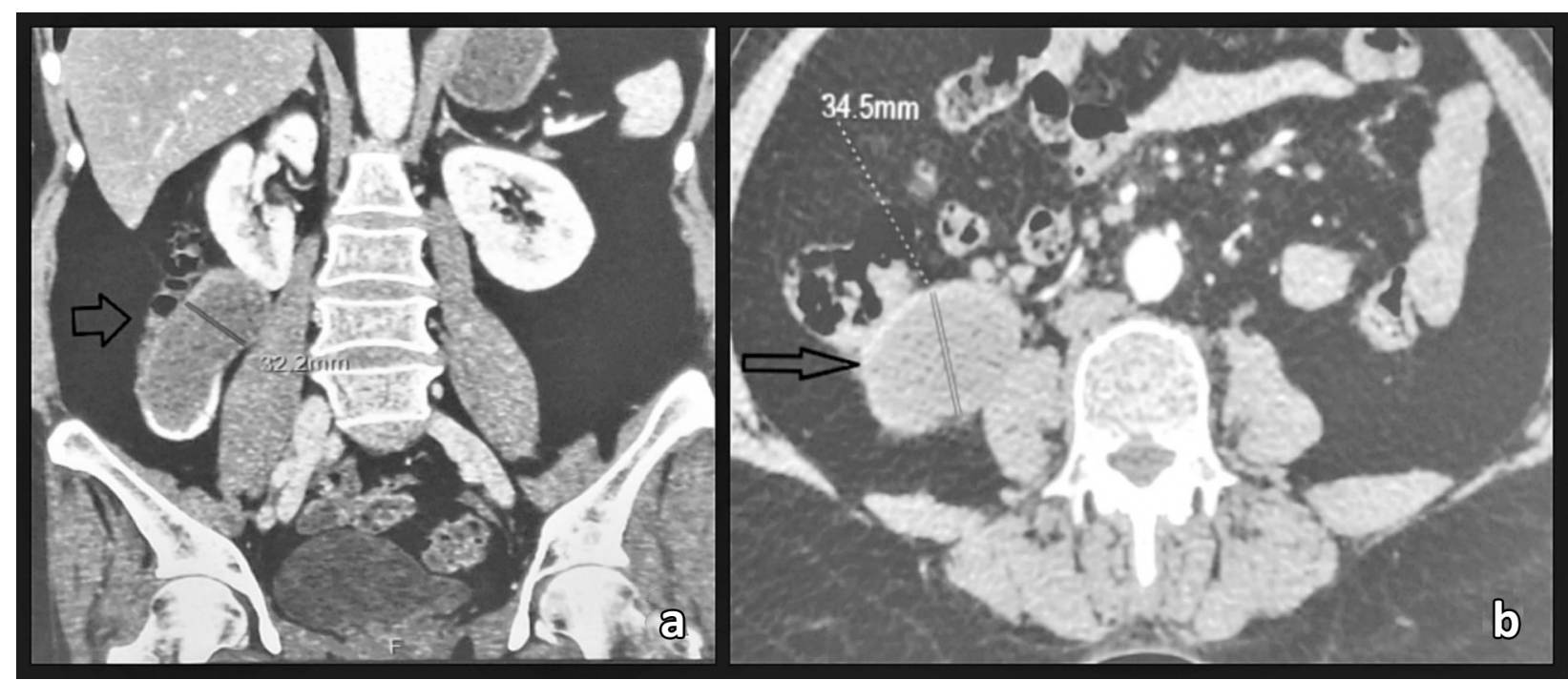

Figure 1: a. Coronal CT, b. Axial CT scan showing the typical appearance of an appendeceal mucocele with cystic content and mural calcifications.

obstructing pathologies - mucinous cystadenoma (63\%), mucosal hyperplasia (25\%), mucinous cystadenocarcinoma (11\%) and mucus retention cyst or lumen occlusion by carcinoid tumor? ${ }^{7}$. With female preponderance, it is most common in the sixth or seventh decade of life ${ }^{8}$.

The common presenting symptoms of $A M$ are episodic right lower quadrant abdominal pain, abdominal mass, weight loss and change in bowel habits. Complications include intussusception, bleeding, perforation, peritonitis and pseudomyxoma peritone $\mathrm{j}^{9,10}$.

CT is the investigation of choice. The typical CT appearance of AM is a well-circumscribed, smooth, thin walled mass with or without mural calcification located in the right iliac fossa. Regardless of the etiology, there may be variation in thickness of the wall of the mucocele and density depending on the contents. Most mucoceles have a low cystic watery density with possibility of high soft tissue attenuation. The most important feature is no exhibition of signs of periappendicular inflammation or collection ${ }^{8,11-13}$. Typical mural calcification on a CT is seen only in half of the cases ${ }^{9,14,15}$. Oval shaped cystic mass on ultrasound with acoustic shadow of mural calcification- "onion ring" is a typical finding. Like in CT, there is no sign of inflammation or periappendicular collection ${ }^{14-17}$. MRI is inferior in detecting calcifications compared to CT. Low sensitivity of FDG PET in detecting appendeceal carcinoma limits its use in workup of $\mathrm{AM}^{18,19}$.

\section{Conclusion}

Differentiating benign from malignant mucocele of appendix with modern radiological modalities is still a formidable challenge. Surgery with complete resection of the appendix is sufficient for retention cyst, cystoadenoma and mucosal hyperplasia. For cystadenocarcinoma, choice of treatment depends on the extent of the disease - if no mesenteric or other organ involvement is seen then resection is enough for complete cure ${ }^{20}$.

\section{References}

1. Rangarajan M, Palanivelu C, Kavalakat AJ, Parthasarathi R. Laparoscopic appendectomy for mucocele of the appendix. Report of 8 cases. Indian J Gastroenterol. 2006;25(5):256-7.

2. Smeenk RM, van Velthuysen ML, Verwaal VJ, Zoetmulder FA. Appendiceal neoplasms and pseudomyxoma peritonei: A population-based study. Eur J Surg Oncol. 2008;34(2):196-201.

3. Lien WC, Huang SP, Chi CL, Liu KL, Lin MT, Lai Tl, et al. Appendiceal outer diameter as an indicator for differentiating appendiceal mucocele. Am J Emerg Med. 2006;24(7):801-5.

4. Stocchi L, Wolff BG, Larson DR, Harrington JR. Surgical treatment of appendiceal mucocele. Arch Surg. 2003;138(6): 585-59.

5. Ruiz-Tovar J, Teruel DG, Castiñeiras VM, Dehesa AS, Quindós PL, Molina EM. Mucocele of the appendix. World J Surg. 2007;31(3):542-8.

6. Rokitansky CF. A Manual of Pathological Anatomy. Vol. 2. Philadelphia: Blanchard \& Lea, 1855 
7. Higa E, Rosai J, Pizzimbono CA, Wise L. Mucosal hyperplasia, mucinous cystadenoma and mucinous cystadenocarcinoma of the appendix. A reevaluation of appendiceal "mucocele". Cancer. 1973;32(6):1525-41.

8. Viswanath $Y K$, Griffiths $C D$, Shipsey D, Oriolowo A, Johnson SJ. Myxoglobulosis, a rare variant of appendiceal mucocele, occurring secondary to an occlusive membrane. J R Coll Surg Edinb. 1998;43(3):204-6.

9. Dachman $\mathrm{AH}$, Lichtenstein JE, Friedman $\mathrm{AC}$. Mucocele of the appendix and pseudomyxoma peritonei. AJR Am J Roentgenol. 1985;144(5): 9239.

10. Huang HC, Liu TP, Jeng KS. Intussusception of mucocele of the appendix: A case report. Zhonghua Yi Xue Za Zhi (Taipei). 1994; 53(2):120-3.

11. Kim SH, Lim HK, Lee WJ, Lim JH, Byun JY. Mucocele of the appendix Ultrasonographic and CT findings. Abdom Imaging. 1998;23(3):292-6.

12. Madwed D, Mindelzun R, Jeffrey RB Jr. Mucocele of the appendix: Imaging findings. Am J Roentgenol. 1992;159(1):69-72.

13. Zissin R, Gayer G, Kots E, Apter S, Peri M, ShapiroFeinberg $\mathrm{M}$. Imaging of mucocoele of the appendix with emphasis on the CT findings: A report of 10 cases. Clin Radiol. 1999;54(12): 826-32.
14. Attarde V, Patil P, Apte A, Barhate K, Gandhe A, Sorte $S$, et al. Sonographic appearance of a giant appendicular mucocele. J Clin Ultrasound. 2011;39(5):290-2.

15. Pickhardt PJ, Levy AD, Rohrmann CA Jr, Kende Al. Primary neoplasms of the appendix: Radiologic spectrum of disease with pathologic correlation. Radiographics. 2003;23(3):645-62.

16. Francica G, Lapiccirella G, Giardiello C, Scarano F, Angelone G, De Marino F, et al. Giant mucocele of the appendix: Clinical and imaging findings in 3 cases. J Ultrasound Med. 2006;25(5):643-8.

17. Caspi B, Cassif E, Auslender R, Herman A, Hagay Z, Appelman $Z$, et al. The onion skin sign: A specific sonographic marker of appendiceal mucocele. J Ultrasound Med. 2004;23(1): $\quad$ 117-21.

18. Purandare NC, Gandhi A, Puranik AD, Agrawal A, Shah S, Patil A, et al. Use of FDG/PET CT to diagnose malignancy as the cause of mucocele of the appendix. Indian J Gastroenterol. 2014;33(1):79-81.

19. Rohani P, Scotti SD, Shen P, Stewart JH, Russell $\mathrm{GB}$, Cromer $\mathrm{M}$, et al. Use of FDG-PET imaging for patients with disseminated cancer of the appendix. Am Surg. 2010;76(12):1338-44.

20. Soweid AM, Clarkston WK, Andrus $\mathrm{CH}$, Janney CG. Diagnosis and management of appendiceal mucoceles. Dig Dis. 1998;16(3):183-6. 